\title{
CONSIDERAÇÕES ACERCA DA LEGITIMIDADE RÉGIA DE ALFREDO, O GRANDE, REI DOS ANGLO-SAXÕES NA BRITÂNIA DO SÉCULO IX.
}

\author{
Monah Nascimento Pereira ${ }^{1}$
}

Alfredo foi rei de Wessex no período de 871 a 899, sendo que terminou seu reinado como rei dos Anglo-Saxões, o regente dominante na Britânia ${ }^{2}$ Medieval. Teve atuação destacada em aspectos políticos, militares e culturais, motivos pelos quais recebeu o epíteto "O Grande", nunca associado a nenhum outro monarca desta região. Isso ocorreu de forma tardia, sendo que durante sua época ele não possuía essa denominação. Foi posteriormente que se procurou atribuir a ele tal epíteto, o que, não obstante, não significa que não fosse valorizado por seus contemporâneos e sucessores imediatos. Em realidade, todos os seus feitos, especialmente seu sucesso em conter as invasões nórdicas no sul das ilhas britânicas, permitiram uma posterior unificação da Inglaterra, o que acabou por ser mais valorizado apenas em um período posterior, quando o monarca foi considerado também o pai da marinha inglesa.

Nascido em 849, Alfredo era o filho mais novo do então rei Æthelwulf, o que não o tornava o primeiro a ser designado para subir ao trono. De fato, seus quatro irmãos mais velhos tinham a preferência, mas ante a morte de dois deles, tomar conta do reino tornou-se uma tarefa de Æthelred e Alfredo, que dividiam as funções administrativas. Em 871, com a morte de seu último irmão varão,

\footnotetext{
${ }^{1}$ Graduanda em História pela UFPR, sob orientação da Professora Doutora Fátima Regina Fernandes.

2 Optamos por utilizar a nomenclatura "Britânia" ao invés do termo "Inglaterra", muitas vezes utilizados pelos autores que tratam desse período. Tal opção se deve ao fato de a Inglaterra como concebemos hoje não ser a formação política que se configurava na época, não sendo mais que, talvez, um projeto. Da mesma maneira, não foi utilizado o termo "Bretanha", pois este está associado a uma específica região litorânea do que hoje conhecemos como França.
} 
Alfredo sucedeu ao trono em uma situação bastante complicada, já que o "exército de incursão pagão"3 dos Daneses estava para ser reforçado pela chegada de mais homens vindos do Norte. Na guerra pela sobrevivência dos reinos anglo-saxões já se tinham perdido muitos homens e os sobreviventes se encontravam exaustos.

Além de todos estes fatores, o jovem monarca também sofria com alguns problemas pessoais, como o aparecimento de uma doença súbita (que o afligiria até o fim de sua vida) e as reivindicações de seus dois sobrinhos, que poderiam lhe contestar o direito de reinar.

Ao se analisar o reinado de Alfredo é preciso levar em conta o contexto histórico em que se insere, com destaque especial para questões regionais que moldaram a configuração política da Britânia no século IX. Até o primeiro quarto do século IX, o reino de Mércia, imediatamente ao norte de Wessex, era o centro político da Britânia, sendo que dominava muitos outros reinos menores ao redor. Wessex era um reino independente, mas não possuía a importância política do vizinho. Isso se modificou a partir do reinado do avô de Alfredo, Egbert, que derrotou os mércios, alterando o panorama então vigente. Os territórios que antes se encontravam sob o julgo de Mércia estavam agora submetidos a Wessex, que aumentou consideravelmente seu território e a influência política que exercia.

Paralelamente, as invasões nórdicas ganhavam cada vez mais força, sendo que as campanhas militares eram bastante freqüentes. Ao governante de Wessex era atribuído um papel essencial nessa conjuntura. O reino mais poderoso da Britânia precisava ser capaz de repelir os ataques, resguardando o território dos saxões do oeste ${ }^{4}$ e, em ultima instância, apoiar seus vizinhos também. Mesmo antes de chegar ao trono, Alfredo já estava envolvido nessas batalhas, sendo comandante do exército ao lado de seu irmão e, até então rei, Æthelred.

\footnotetext{
3 “heathen raiding-army". Cf. SWANTON, Michael. The Anglo-Saxon Chronicles. London: Phoenix, 2000. p. 68.

${ }^{4}$ Refere-se ao povo de Wessex e arredores imediatos.
} 
Nesse sentido, estes elementos básicos apresentados devem ser observados: uma diminuição da importância do reino de Mércia no panorama político em detrimento de uma nova supremacia de Wessex e, obviamente, as invasões dos homens do norte, iniciadas ainda no século VIII.

A grande extensão de Wessex tornou a sucessão complexa, sendo que Æthelwulf dividiu o reino com seu filho mais velho ainda em vida. Este veio a falecer no início da década de 50 e, antes da sua própria morte, o rei dividiu o reino entre seus outros dois filhos mais velhos. Após uma sucessão de mortes, Alfredo foi o único filho de Æthelwulf a continuar vivo, tornando-se rei de Wessex em 871. Seus sobrinhos, obviamente, tinham restrições quanto ao novo governante.

Por conta de todos estes fatores aqui expostos, torna-se importante analisar não apenas as circunstâncias em que Alfredo assumiu o poder, mas também a forma como este ato foi visto e difundido. A ascensão do monarca ao trono foi descrita em diversas fontes, sendo que as Crônicas Anglo-Saxônicas ${ }^{5}$ a apresentam de maneira clara e incontestável. Esta fonte seria, basicamente, os anais que registram os acontecimentos mais importantes do povo em questão, com ênfase nas questões políticas, militares e religiosas, descritas com base em uma ordem cronológica dos anos. No registro de 871 consta a morte de Æthelred, um bom rei durante os cinco anos em que governou. Logo em seguida aparece como conseqüência direta a coroação de Alfredo, que assume a posição de seu irmão. Inicialmente o silêncio em relatar qualquer contratempo faz parecer que não houve qualquer dificuldade para se concretizar esse fato, o que, todavia, não foi exatamente dessa forma.

As duas outras fontes utilizadas apresentam uma descrição mais alongada desse processo, o que permite analisar com mais vagar a questão da sucessão. A primeira fonte em questão é a Asser's life of

${ }^{5}$ SWANTON, op. cit., p. $72-73$. 
king Alfred $^{6}$, escrita aproximadamente em 893 pelo bispo galês Asser, que conviveu diretamente com o rei. Esse texto pode ser caracterizado como uma biografia régia e de fato o é por parte de alguns historiadores que estudam o assunto. Todavia, é passível de nota que tal obra não é homogênea no que diz respeito a sua escrita, já que ela pode ser dividida em duas grandes partes, sendo que a primeira delas é uma transcrição de algumas partes das Crônicas Anglo-Saxônicas, com algumas alterações e acréscimos. A segunda fração da obra trata mais detidamente da figura do próprio rei, falando a respeito de suas virtudes e qualidades. Por mais que se considere esta uma biografia, até por ter sido provavelmente inspirada pela Vita Caroli ${ }^{7}$, é algo bastante complexo inclúi-la em um gênero literário fixo, já que há uma mescla de diversos elementos presentes nas fontes de inspiração de Asser.

O autor faz questão de apontar, ao tratar da sucessão, primeiramente, que o reinado de Alfredo era legítimo, tendo sido aceito primeiramente por Deus e também por todos os habitantes do reino. E acrescentado, inclusive, que Alfredo poderia ter se tornado rei mesmo com seu irmão vivo se quisesse, pois era digno dessa posição, por se tratar do mais inteligente dos irmãos e, sobretudo, ser virtualmente invencível em todas as batalhas. Mesmo sem desejar a guerra, tão numeroso era o exercito pagão, Alfredo se viu empenhado novamente em batalhas contra os nórdicos, sempre contando com a ajuda de Deus, pois sozinho ele não teria conseguido lutar contra todos eles, segundo seu biógrafo.

Essa descrição aponta para uma necessidade de afirmar Alfredo como governante frente ao contexto em que se inseria. Ele é aceito, segundo Asser, por toda a população, mas, mais importante que isso, ele é escolhido por Deus. Dessa forma torna-se

${ }^{6}$ KEYNES, Simon; LAPIDGE, Michael. Alfred the Great: Asser's Life of King Alfred and Other Contemporary Sources. London: Penguin, $2004\left(1^{\text {st }}\right.$ edition: 1983).

${ }^{7}$ Biografia da vida de Carlos Magno, imperador franco de início do século IX.

${ }^{8}$ KEYNES; LAPIDGE, op. cit., p. 80. 
inquestionável a sua legitimidade, já que mesmo durante as batalhas ele, que era exímio guerreiro, contava com a ajuda do divino para vencer tamanha ameaça. O possível objetivo dessa obra seria uma tentativa de convencimento dos galeses, povo de Asser, de que Alfredo era de fato um bom governante, a quem os antigos habitantes da Britânia deveriam se sentir felizes por estarem submetidos ${ }^{9}$, apontando para uma tentativa de legitimar ainda mais o reinado do presente monarca.

O testamento de Alfredo $^{10}$ também aponta nessa direção, sendo que logo no início do documento, antes de começar a tratar da herança que deixaria, o rei descreve também a maneira pela qual chegou ao poder e como recebeu as propriedades de seu irmão, de maneira legítima. Ele conta como pediu sua parte a Æthelred, que disse não poder dividir, pois era algo difícil de se fazer; no entanto, após sua morte garantiu que Alfredo seria o único a receber tais bens, em detrimento dos próprios filhos, que não seriam tão beneficiados. Essa postura já demonstra a primazia de Alfredo no que diz respeito também aos assuntos do reino, sendo ele aquele que receberia o encargo de reinar no caso da morte do irmão, talvez até por sua maior maturidade em relação aos sobrinhos, que eram mais novos. Quando da morte do irmão, ele perguntou a todos se aquilo que fora arranjado entre ele e o falecido estava correto, sendo que os conselheiros aprovavam a decisão, de forma que as propriedades passavam para ele legitimamente, tal qual o trono, coisa que não se apresenta como sendo questionada, mas que está também atrelada à questão das propriedades.

Dessa forma, fica clara a intenção de Alfredo de se colocar como legitimo dono de tais terras, de forma que pudesse, em seu testamento, dividi-las como bem entendesse. Em ambos os casos, é interessante ressaltar que a questão da legitimidade é tratada em

\footnotetext{
9 "Asser intended his Life of King Alfred to reassure the Welsh that they had submitted themselves to a wise, just, effective and Christian King." Cf. KEYNES; LAPIDGE. op. cit., p. 56.

${ }^{10}$ Idem, p. 173-178.
} 
fontes relativamente tardias no que diz respeito ao reinado de Alfredo, já que o texto de Asser é escrito poucos anos antes da morte do rei e que seu testamento não é escrito logo no inicio do reinado, datando de algum ano da década de 80 , provavelmente. Percebe-se então que não existia apenas a necessidade de auto-afirmação e de legitimação de sua figura como rei, mas também com relação a sua descendência. Ressaltando sua própria legitimidade, Alfredo garante que seus filhos não sofram contestações, o que é ainda mais latente no caso da divisão de terras, que poderia não agradar aos seus sobrinhos, como de fato aconteceu ${ }^{11}$. Deve-se pensar que a questão da posse de terras importantes está intimamente ligada com a hierarquia, sendo que é natural que o rei disponha de mais propriedades. O testamento de Alfredo aponta para isso, enquanto que o relato de Asser traz consigo o aspecto legitimador da tradição cristã, de forma que o rei possuía e utilizava diferentes discursos em diferentes situações para demonstrar a validade de seu reinado.

A questão da legitimidade de Alfredo perpassa também outros pontos que podem ser evidenciados a partir do discurso escrito elaborado durante o período alfrediano. Tanto no que diz respeito aos seus documentos legais mas também, e especialmente, na tradição literária desenvolvida em fins do século IX observa-se, além dos idéias particulares do rei, a busca por uma legitimação de sua posição. Alfredo iniciou uma espécie de regeneração moral e religiosa, como se percebe ao observarem-se as leis por ele elaboradas, que estavam baseadas em uma tradição legislativa do Antigo Testamento. Nisso ele foi certamente influenciado pelo ideal de rei cristão presente no continente, desenvolvido especialmente no início da dinastia carolíngia, mais especificamente no reinado de Carlos Magno. Nesse sentido, a maior contribuição feita por Alfredo foi o programa de traduções estabelecido por ele, cujo objetivo era traduzir para o Inglês Antigo textos em Latim que o rei considerava importantes para todo cristão conhecer. Quatro textos, a citar Regula

\footnotetext{
${ }^{11}$ Um dos sobrinhos de Alfredo veio a se rebelar contra seu filho, Eduardo depois que este assumiu o poder. KEYNES; LAPIDGE. op. cit., p. 173.
} 
pastoralis de Gregório Magno, De consolatione Philosophiae de Boécio, Soliloquia de Santo Agostinho e vários dos primeiros Salmos, foram traduzidos pelo próprio monarca; dois outros foram traduzidos sob sua orientação direta, sendo eles Dialogi de Gregório Magno e Historiae adversus paganos de Paulo Orósio, além de seu envolvimento com a tradução de alguns outros textos.

Muitas vezes a tradução alfrediana das obras já mencionadas divergia do texto original em latim, sendo que em alguns momentos passagens eram suprimidas e em outros, especialmente no caso do texto de Agostinho, eram adicionados conteúdos que o rei considerava importantes à sua realidade; adaptando-os e revalidando seu conteúdo, em função de seu contexto. Da mesma maneira, a utilização de textos cristãos de tal importância conferia legitimidade ao reinado de Alfredo, aproximando-o de uma tradição cristã presente no continente. Nas obras traduzidas dois assuntos têm lugar de maior destaque, quer seja por conta de seus autores originais, quer por acréscimo dos tradutores: temas relacionados com liderança e governo e a responsabilidade do governante sobre os outros e a relação humana com Deus, mais especificamente falando do cuidado com a alma. Dessa maneira, torna-se perceptível a importância dada para o aspecto religioso, sempre o relacionando às questões políticas, de forma que o Cristianismo atuasse como um aliado do monarca ante a população. Alfredo destaca em sua obra a importância do papel do rei como representante de Deus na Terra, tradicionalmente trabalhado na teorização do poder pelos cristãos, tendo como base principal o reino franco, que já havia visitado quando criança.

Talvez pelo fato de não ter sido inicialmente preparado para governar, Alfredo teve uma formação que acabou por ressaltar as questões religiosas, tendo ele visitado o Papa em Roma por duas vezes, acontecimentos que seriam sempre lembrados com intuito de fortalecer o reinado do mesmo. Além da influência que recebeu de suas visitas ao Pontificado, foi afetado também por sua passagem pelo reino carolíngio, no qual se baseou em diversos aspectos como, por exemplo, o tratamento dado aos homens do norte. De fato, seu 
pai chegou a contrair matrimônio pela segunda vez com a filha de Carlos, o Calvo, descendente de Carlos Magno. Tudo isso aponta para uma busca de conexões com outras realidades vividas no continente, que partilhavam da tradição em que se pautava Alfredo. De qualquer forma, o elemento da legitimidade sempre figurava como extremamente importante para o monarca, que se utilizava de diferentes aparatos para confirmar a validade e qualidade de seu governo.

$\mathrm{O}$ rei deveria possuir, por exemplo, virtudes militares e também virtudes religiosas para que fosse digno de exercer sua posição. Era preciso que tivesse meios de proteger seu reino, motivo pelo qual a habilidade militar era tida em alta conta; da mesma forma, precisava estar atrelado aos ideais cristãos de virtude, respondendo sempre a Deus, sendo ele seu maior espelho. Tudo isso deve estar aliado ao elemento de aprovação e consentimento daqueles que serão governados, especialmente da nobreza, a parcela politicamente mais importante da população, sem o aval da qual se torna inviável a qualquer monarca governar.

\section{BIBLIOGRAFIA}

KEYNES, Simon; LAPIDGE, Michael. Alfred the Great: Asser's Life of King Alfred and Other Contemporary Sources. London: Penguin, 2004 ( $1^{\text {st }}$ edition: 1983).

SWANTON, Michael. The Anglo-Saxon Chronicles. London: Phoenix, 2000.

CAMPBELL, James (ed.). The Anglo-Saxons. Londres: Pengin, 1991 ( $1^{\text {st }}$ edition: 1982$)$.

HUNTER BLAIR, Peter. An Introduction to Anglo-Saxon England. Cambridge: Cambridge University press, 2003, $3^{\text {rd }}$ edition $\left(1^{\text {st }}\right.$ edition: 1956). 
LAPIDGE, Michael; BLAIR, John; KEYNES, Simon and SCRAGG, Donald (ed.). The Blackwell Encyclopaedia of Anglo-Saxon England. Oxford: Blackwell Publishing, 2001.

LE GOFF, J.; SCHIMITT, J.-C. Dicionário temático do ocidente medieval. Bauru: EDUSC, 2002. 